\title{
ANTROPOLOGIA COM IMAGENS: \\ CARTAS AOS NARRADORES URBANOS E O LIVRO DO ETNÓGRAFO
}

\author{
ANA LUIZA CARVALHO DA ROCHA \\ CORNELIAECKERT ${ }^{2}$ \\ MARINA BORDIN BARBOSA ${ }^{3}$ \\ MATHEUS CERVO ${ }^{4}$
}

\begin{abstract}
RESUMO
Inspirados pelos estudos piagetianos e durandianos sobre a inteligência e o imaginário, relatamos experiências do ensino da disciplina de Antropologia Visual e da Imagem e de Antropologia Urbana no Curso de Ciências Sociais e no Programa de Pós-Graduação em Antropologia Social na Universidade Federal do Rio Grande do Sul. Estas pesquisas são desenvolvidas no Núcleo de Antropologia Visual (Navisual) e no Banco de Imagens e Efeitos Visuais (BIEV), projetos coordenados pelas Professoras Cornelia Eckert e Ana Luiza Carvalho da Rocha. A fim de demonstrar diferentes propostas de ensino-aprendizagem na produção de etnografias na e da cidade de Porto Alegre, expomos dois projetos produzidos por alunos e professores em que diferentes recursos - escritos, imagéticos e hipermidiáticos - são mobilizados para expressão do trabalho de campo: a exposição denominada "Carta aos Narradores Urbanos: etnografia de rua na Porto Alegre das intervenções artísticas" e o projeto hipermídia intitulado "Livro do Etnógrafo".
\end{abstract}

\section{PALAVRAS-CHAVE:}

Ensino; Cidade; Imagem; Expografia; Hipermídia.

\footnotetext{
1 Atua como professora colaboradora no Programa de Pós-graduação em Antropologia Social/PPGAS/IFCH da Universidade Federal do Rio Grande do Sul/UFRGS, e como professora do quadro permanente da Universidade Feevale/RS, no Programa de Pós-graduação em Diversidade cultural e Inclusão social e de Processos de Manifestações Culturais.

2 Atua como professora no Departamento de Antropologia, no Programa de Pós-graduação em Antropologia Social, do IFCH, e no Programa de Pós-graduação em Ecologia, UFRGS.

${ }^{3}$ Mestranda no Programa de Pós-graduação em Antropologia Social na Universidade Federal do Rio Grande do Sul (PPGAS/UFRGS) e integrante do Núcleo de Antropologia Visual (NAVISUAL/PPGAS/UFRGS).
}

${ }^{4}$ Atual graduando em Ciências Sociais na Universidade Federal do Rio Grande do Sul. Participa como bolsista de inovação tecnológica e iniciação científica na construção de coleções etnográficas hipermídia no Banco de Imagens e Efeitos Visuais (BIEV/PPGAS/UFRGS). Рara mais informações referentes aos autores, acessar biev.ufrgs.br. 


\title{
ANTRHROPOLOGY WITH IMAGES: A LETTER TO THE URBAN NARRATORS AND THE ETHNOGRAPHER'S BOOK
}

\begin{abstract}
Inspired by the Piagetian and Durandian studies on intelligence and imagery, we report on the teaching of the discipline of Visual Anthropology and Urban Anthropology in the graduation course of Social Sciences and the Postgraduate Program in Social Anthropology at the Federal University of Rio Grande do Sul. These researches are developed at the Center of Visual Anthropology (Navisual) and at the Bank of Images and Visual Effects (BIEV), projects coordinated by Professors Cornelia Eckert and Ana Luiza Carvalho da Rocha. In order to demonstrate different teaching-learning proposals in the production of ethnographies in and of the city of Porto Alegre, we present two projects produced by students and teachers in which different media - written, imagery and hypermedia - are mobilized to express the field work: the exhibition entitled "Letter to Urban Narrators: Street Ethnography in Porto Alegre of Artistic Interventions" and the hypermedia project entitled "Ethnographer's Book".
\end{abstract}

\section{KEYWORDS}

Teaching; City; Image; Expography; Hypermedia.

\section{ANTROPOLOGÍA CON IMÁGENES: CARTAS A LOS NARRADORES URBANOS Y EL LIBRO DEL ETNÓGRAFO}

\section{RESUMEN}

Inspirados por los estudios piagetianos y durandianos sobre la inteligencia y el imaginario, relatamos experiencias de la enseñanza de la disciplina de Antropología Visual y de la Antropología Urbana en el Curso de Ciencias Sociales y en el Programa de Postgrado en Antropología Social en la Universidad Federal de Rio Grande del Sur. Estas investigaciones se desarrollan en el Núcleo de Antropología Visual (Navisual) y en el Banco de Imágenes y Efectos Visuales (BIEV), proyectos coordinados por las Profesoras Cornelia Eckert y Ana Luiza Carvalho da Rocha. Con el fin de demostrar diferentes propuestas de enseñanza-aprendizaje en la producción de etnografías en la ciudad de Porto Alegre, exponemos dos proyectos producidos por alumnos y profesores en que diferentes recursos son movilizados para expresión del trabajo de campo: la exposición "Carta a los Narradores Urbanos: etnografía de calle en Porto Alegre de las intervenciones artísticas" y el proyecto"Libro del Etnógrafo".

\section{PALABRAS CLAVE}

Enseñanza; Ciudad; Imagen; Expografía; Hipermedia. 


\section{RESUMÉ}

Inspiré par le piagétienne et durandianne études sur l'intelligence et de l'imagination, nous présentons des expériences d'enseignement discipline Visual Anthropologie et Anthropologie Urbaine en sciences sociales Cours et le programme d'études supérieures en anthropologie sociale à l'Université Fédérale de Rio Grande do Sul. Ces enquêtes sont développés dans le Centre d'anthropologie visuelle (Navisual) et la Banque d'images et effets visuels (BIEV), projets coordonnés par les professeurs Cornelia Eckert et Ana Luiza Carvalho da Rocha. Afin de démontrer différentes approches pédagogiques et d'apprentissage dans la production de ethnographies sur et dans la ville de Porto Alegre, nous exposons deux projets réalisés par les étudiants et les enseignants des différentes ressources écrite, picturale et hypermédia - sont mobilisées pour expression de l'ethnographie: l'exposition intitulée « Lettre à Storytellers Urban ethnographie rue dans les interventions artistiques Porto Alegre " et projet hypermédia intitulé « livre de l'ethnographe ».

\section{MOTS CLÉ}

Enseignement; Ville; Image; Expographie; Hypermédia. 


\section{INTRODUÇÃO}

Inspirados pelos estudos piagetianos e durandianos sobre a inteligência e o imaginário, relatamos experiências do ensino da disciplina de Antropologia Visual e da Imagem e de Antropologia Urbana no Curso de Ciências Sociais e no Programa de Pós-Graduação em Antropologia Social na Universidade Federal do Rio Grande do Sul. Nas duas primeiras seções trazemos relatos de experiências do Núcleo de Antropologia Visual (Navisual) e do Banco de Imagens e Efeitos Visuais (BIEV) em projetos coordenados pelas Professoras Cornelia Eckert e Ana Luiza Carvalho da Rocha. A fim de demonstrar diferentes propostas de ensinoaprendizagem na produção de etnografias na e da cidade de Porto Alegre, expomos dois projetos produzidos por alunos e professores em que diferentes recursos - escritos, imagéticos e hipermidiáticos - são mobilizados para expressão do trabalho de campo: a exposição denominada "Carta aos Narradores Urbanos: etnografia de rua na Porto Alegre das intervenções artísticas" e o projeto hipermídia intitulado "Livro do Etnógrafo".

\section{NAVISUAL E A EXPOSIÇÃO "CARTAS AOS NARRADORES URBANOS: ETNOGRAFIA DE RUA NA PORTO ALEGRE DAS INTERVEnções ARTísticas"}

Às vésperas de completar 30 anos de existência, o Navisual tem um processo de ensino caracterizado pelo desenvolvimento de atividades sobre Antropologia Visual e da Imagem. As oficinas são estruturadas a cada início de semestre a partir da coordenação de Cornelia Eckert que incita o debate entre alunos e professores a fim de traçar interesses em comum. No esforço de um exercício etnográfico para pensar conceitos da Antropologia Urbana, o núcleo, em parceria com o Departamento de Difusão Cultural da UFRGS, realizou o projeto "Cartas aos Narradores Urbanos: etnografia de rua na Porto Alegre das intervenções artísticas", exposição realizada na Reitoria da universidade entre novembro de 2017 a janeiro de 2018 com a curadoria de Rafael Derois. A partir da leitura de textos de autores clássicos e contemporâneos, sendo eles Walter Benjamin, Michel de Certeau, Colétte Pétonnet, William Foote Whyte, José G. C. Magnani, Hélio R. S. Silva, Ricardo Campos, Ana Luiza Carvalho da Rocha e Cornelia Eckert, foram elegidas categorias para guiar os percursos do grupo na cidade através de um exercício de câmera na mão tal como a etnografia de rua propõe (ECKERT\&ROCHA, 2013b).

Revista Mundaú, 2018, n.5, p.179-201 
Fig. n 1: Capa da Revista Fotocronografias, v. 02 , n. 03 (2017).

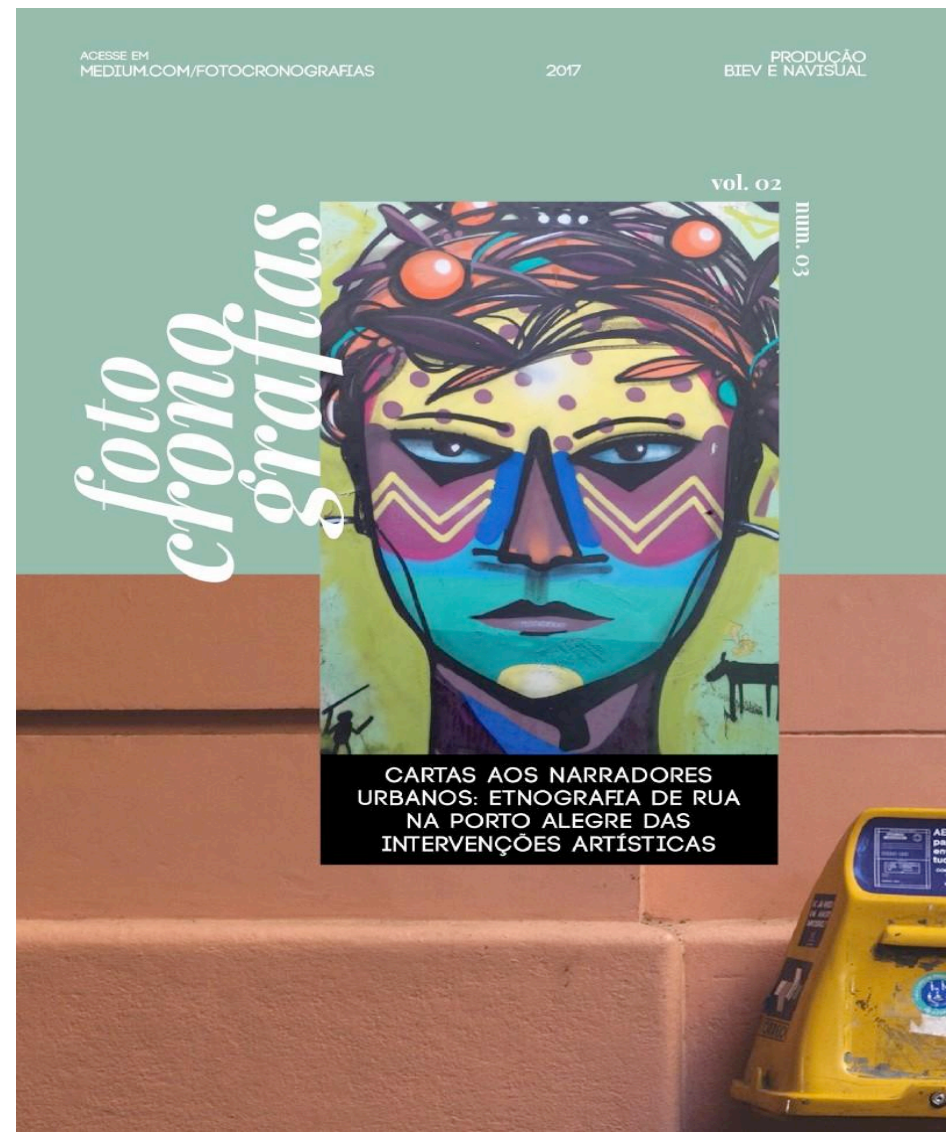

Fonte: Todo conteúdo da exposição pode ser acessado em medium.com/fotocronografias

Foram realizadas quatro saídas de campo. A primeira sucedeu nas ruas do bairro Cidade Baixa, antiga região de quilombos que hoje é conhecida pelas práticas boêmias e pelos grafites espalhados nos muros. O grafiteiro Tridente guiou o percurso junto à equipe que tinha, durante o período, o professor Ricardo Campos da Universidade Nova de Lisboa como colaborador do projeto e cujo grafite é um dos seus principais objetos de estudo.

A segunda e a terceira saídas de campo foram realizadas na região conhecida como $4^{\circ}$ distrito. O projeto vigente no Navisual, naquele período, consistia em pensar o $4^{\circ}$ distrito de Porto Alegre, um antigo polo industrial e operário da cidade que atualmente passa por um período de degradação e, simultaneamente, revitalização em algumas áreas. O grafite também foi um dos temas em destaque devido aos painéis desenvolvidos pelo projeto ZisGrafite, a partir de um edital da prefeitura de Porto Alegre. A região, atualmente, é conhecida como um polo de Economia Criativa em construção na cidade. Incentivos como isenção de IPTU para projetos de 
Economia Criativa tem feito com que cada vez mais indivíduos das áreas de artes, sustentabilidade, tecnologia e criação busquem alojar-se nesta área. Um dos principais projetos nesse âmbito é o complexo cultural Vila Flores, uma iniciativa privada de escritórios e coworking.

Por último, a quarta saída de campo teve o bairro Centro Histórico como cenário. A caminhada iniciou-se às margens do muro do Cais Mauá, construído durante a metade do século XX a fim de evitar os grandes alagamentos nessa região após o aterramento de boa parte do Rio Guaíba ${ }^{5}$. Atualmente, o muro é coberto por grafites institucionalizados financiados pela prefeitura de Porto Alegre. Nessa região, também conhecemos uma antiga residência que hoje abriga um museu a céu aberto de grafite, conhecido como Vila Formiga, localizado ao lado de outro projeto da comunidade: a Horta Comunitária.

Em cada percurso, o grupo foi acompanhado por interlocutores que possuíam familiaridade com o bairro e com projetos concentrados na região específica. Apenas no $4^{\circ}$ distrito, o caminho do ZisGrafite foi guiado por um aplicativo no celular que indicava o trajeto a partir de placas de QR Code ${ }^{6}$. Além disso, indivíduos itinerantes que interagiram com o grupo nesses percursos tornaram-se personagens na etnografia. A etapa que sucedeu as saídas de campo foi a elaboração da expografia. Mergulhados em uma constelação de miniaturas, o processo de escolhas das imagens para compor a narrativa de cada autor estudado passou por diversas etapas de seleção. O Navisual utiliza o método de curadoria compartilhada que objetiva a criação de coleções com base em fragmentos de memória. O método da convergência, como é conhecido, busca atribuir núcleos de sentidos aos fragmentos a partir de categorias selecionadas. Batizado por Bergson, o método da convergência envolve sempre a atuação coletiva para a organização dos núcleos semânticos em categorias de sentidos. Esse processo coincide em pensar as camadas da duração de Bachelard e potencializar a imaginação criadora de Gilbert Durand no que se constitui como a Etnografia da Duração (2013a).

A seleção das imagens foi realizada pela equipe do Navisual, autores das imagens da exposição. A leitura dos textos dos autores permitiu a criação de uma tabela de conceitos de cada autor para pensar as imagens que iriam compor cada narrativa. A segunda etapa da expografia foi pensar a estética das coleções de miniaturas que iriam transmitir sucintamente a ideia de cada autor.

\footnotetext{
${ }^{5}$ Lago conhecido popularmente como rio, às margens de Porto Alegre - RS.

${ }^{6}$ Código QR (sigla do inglês Quick Response, reposta rápida em português) é um código de barras bidimensional que pode ser facilmente escaneado usando a maioria dos telefones celulares equipados com câmera.
} 
Com o intuito de ser um projeto multi-instrumental, a parte seguinte do projeto constituiu em oficinas para a elaboração de desenhos dos autores que foram transformados em adesivos. A artista plástica Rumi Kubo, também professora colaboradora do Navisual, ministrou oficinas de desenho para a elaboração de caricaturas da fisionomia dos autores. Em seguida, foram eleitas as melhores caricaturas de cada autor para serem impressas em pequenos adesivos que foram espalhados pela exposição.

A última etapa foi a escritura das cartas aos narradores urbanos, processo que nomeou nossa exposição. Aproximando-nos dos autores, as cartas discutiam os conceitos e as imagens que foram escolhidas para compor o percurso etnográfico contado a partir das problematizações desses narradores. A proposta da professora Cornelia Eckert era de pensar a cidade a partir da etnografia da duração: quais imagens prosperam das leituras dos narradores urbanos escolhidos e que levam a uma nova explosão de imagens ao pensar a cidade de Porto Alegre? Da mesma forma, ao pensar a cidade, Gilbert Durand reflete sobre "como o imaginário está sempre convergido com a memória coletiva" (ECKERT \& ROCHA, 2013a, p. 6).

Fig. $n^{0}$ 2: Fundos da Escola EEEF Camila Furtado Alves no bairro Floresta na rua Almirante Barroso, 79.

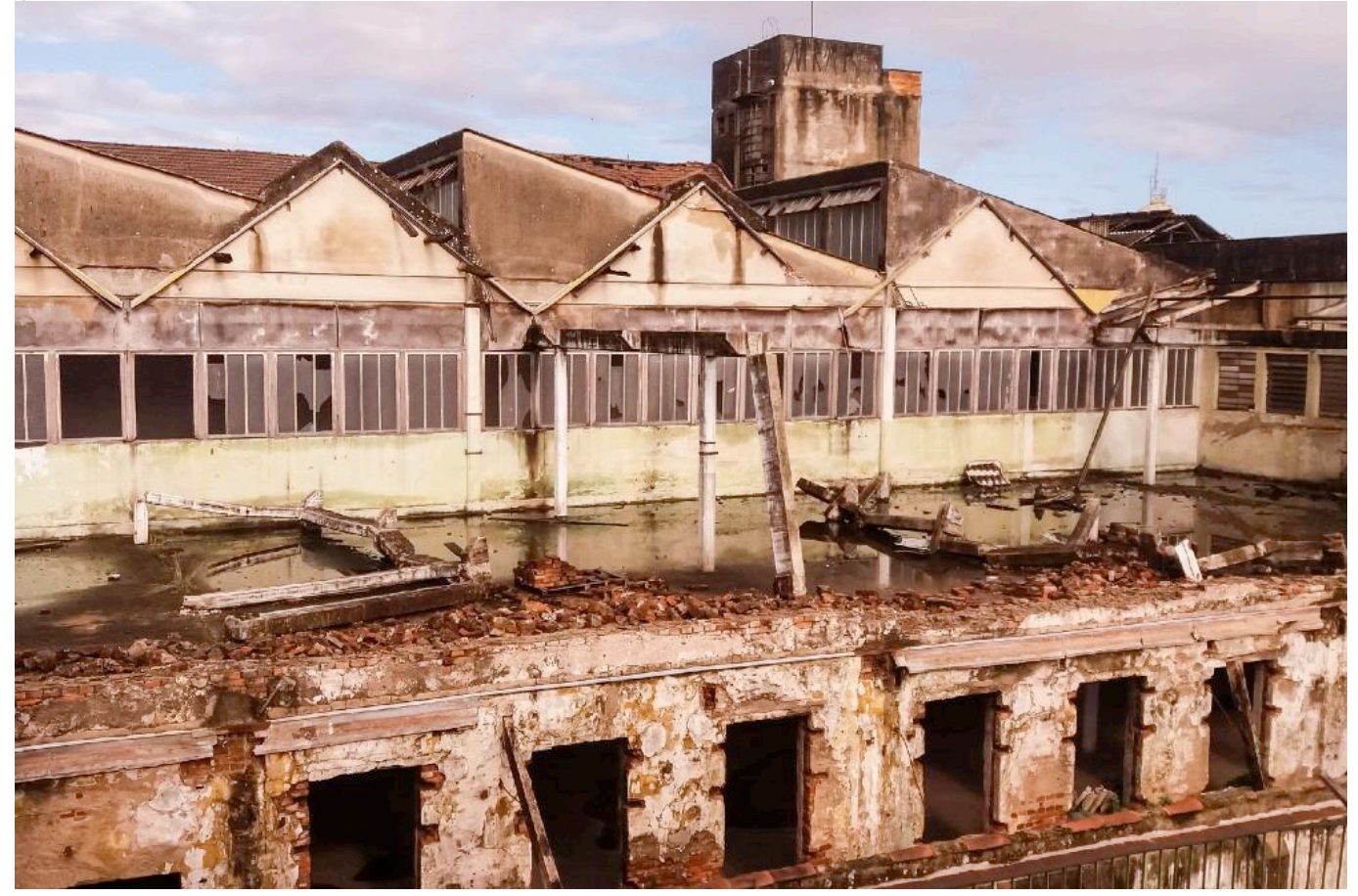

Fonte: Fotografia de Nicole Rigon capturada durante a etnografia realizada no quarto distrito.

A etnografia de rua, pensada pelas autoras Cornelia Eckert e Ana Luiza Carvalho da Rocha (2013b), é fruto das observações das autoras sobre os escritos de pensadores como W. 
Benjamin (1989) e o seu personagem urbano, o flâneur, e C. Pétonnet (2008) com a sua proposta da observação flutuante. Flâneur, para Benjamin (1989) é um andarilho que caminha pelas grandes metrópoles urbanas, observando as vitrines, as avenidas, os bulevares, as ruínas, os indivíduos, desfrutando da liberdade do anonimato que as grandes multidões urbanas proporcionam. Inspirado nos poemas de Baudelaire, a flânerie instiga a pensar as influências do capitalismo na formação do perfil do indivíduo moderno.

De outro modo, a proposta metodológica de observação flutuante de Pétonnet (2008) é uma contribuição ao método de observação participante. Em uma saída de campo com uma turma de Antropologia no cemitério Père Lachaise, Collete desenvolveu o método do "acaso", ou seja, deixar-se levar pelas surpresas encontradas em campo, sem um trajeto engessado ou uma proposta definitiva. A observação flutuante conduziu a turma de antropólogos no cemitério a conhecer uma teia de redes de sociabilidades de senhoras que se organizavam para alimentar os gatos que ali viviam.

Também formaram o grupo de narradores urbanos autores como Ricardo Campos (2010) e sua contribuição com os conceitos de gramáticas visuais e domesticação do grafite. Passou a estudar grafite em Lisboa a partir dos estudos de juventude urbana e periferia. Seus estudos de "pixelização dos muros" (CAMPOS, 2012) também contribuiu para pensar a relação da arte urbana com as tecnologias digitais, como os registros em redes sociais que delimitam, em parte, a efemeridade do picho. A sua presença como professor colaborador no projeto levou o grafite a ser um dos principais temas abordados nas saídas de campo.

José G. C. Magnani (1984), conhecido pelos estudos desenvolvidos no NAU-USP, contribuiu com os conceitos de manchas, pedaços, circuitos e trajetos na caracterização dos espaços urbanos. Ao investigar as diferentes configurações de lazer dos indivíduos e formas de apropriação dos espaços na cidade, Magnani busca uma reflexão nos contrastes entre os espaços públicos e privados nas grandes metrópoles, os símbolos e redes de significados nos grupos sociais e o papel dos equipamentos urbanos como elementos que influenciam na estética e na experiência urbana.

Representando o Rio de Janeiro, o narrador urbano Hélio R. S. Silva trouxe temas como a boemia, meninos de rua, prostituição e transexualidade para os estudos urbanos. No livro "Travesti: a invenção do feminino" (SILVA, 1993), Hélio percorre o bairro da Lapa em busca de seus interlocutores a fim de entender a dinâmica do trabalho e a construção de suas identidades.

Whyte (2005), narrador da antropologia urbana norte-americana, pesquisou sobre gangues que se formavam nas esquinas de bairros italianos em uma região pobre de Boston. A 
partir da interação com o seu principal interlocutor, chamado Doc, descobriu redes de reciprocidade, cooperação e lealdade entre os habitantes daquele bairro, estereotipado como "desordem".

Por último, o francês Michel De Certeau também compõe o grupo de narradores urbanos. Indispensável para os estudos de cidade, o autor discorre sobre a ação narrativa do ato de caminhar. Passos, percursos, trajetos e retóricas caminhatórias são alguns dos termos buscados na obra "A Invenção do Cotidiano" (1980). Segundo De Certeau, "o ato de caminhar está para o sistema urbano como a enunciação (o speech act) está para a língua ou para os enunciados proferidos. (...) é um processo de apropriação do sistema topográfico pelo pedestre" (DE CERTEAU, 1998, p. 177).

Nesse sentido, em um primeiro momento, o projeto apoiou-se em uma pesquisa de caráter bibliográfico e, posteriormente, seguiu para um caráter etnográfico com a realização das quatro saídas de campo. Foram utilizados como instrumentos a câmera fotográfica, equipamentos de som, diário de campo e desenho. Os registros de vídeo e som da primeira saída de campo no bairro Cidade Baixa resultaram em um vídeo da exposição: "Crônica com Tridente", dirigido por Diogo Dubiela. O processo de ensino-aprendizagem resultou em uma publicação impressa de um livro-catálogo da exposição. Produzido por Rafael Derois, que também ministrou oficinas de InDesgin sobre diagramação para a equipe, o catálogo foi lançado no $18^{\circ}$ Congresso IUAES em Florianópolis, onde também esteve em exibição a exposição.

Além de cumprir com o seu intuito de ser um núcleo de formação, o NAVISUAL aprimorou o seu laço afetivo com a cidade e ao mesmo tempo que contribuiu para a área de estudos sociais nas ciências humanas, incentivando o uso das ferramentas de áudio, vídeo e softwares de criação na produção antropológica junto aos artigos científicos.

\section{O LiVRO dO EtNóGRAFO E AS COLEÇÕES ETNOGRÁFICAS HIPERMÍdIA NO BIEV}

Originado a partir da preocupação com a digitalização de acervos imagéticos para construção de coleções etnográficas, a identificação do BIEV enquanto espaço para discussão das prioridades do resgate de conjuntos documentais não é fortuita. O construto que originou o núcleo objetivou, como um de seus eixos de pesquisa, o compartilhamento de acervos hipermídia sobre a cultura urbana portoalegrense no qual são envolvidas questões tanto de direitos autorais quanto de classificação da informação. 
Os procedimentos de tratamento documental adotados tiveram a inspiração no método de convergência ${ }^{7}$ desenvolvidos nos estudos de antropologia do imaginário (DURAND, 1984), a partir da adoção de um estruturalismo figurativo (DURAND, 1979). Nessa perspectiva, o dado etnográfico (no nosso caso, multimídia) nunca é pensado de forma isolado, mas sempre no interior, inicialmente, de coleções e, posteriormente, de constelações de imagens.

Disto resulta a etnografia da duração (ECKERT \& ROCHA, 2013a) como possibilidade de comportar o semantismo das imagens, expresso nas narrativas e ações dos citadinos sobre seus territórios de vida. A narrativa, vocação do sujeito pensante, em seu desejo de transcender o tempo e de eufemizar a mudança em puro deslocamento, na sua condição de estrutura sintética da imaginação humana, revela-se, assim, parte integrante (e integradora) dos estudos antropológicos da memória coletiva nas modernas cidades contemporâneas. Por seu intermédio, observamos a angústia existencial que secreta toda cidade moderna se transformar na expressão rítmica de contrastes de tempos passados e tempos futuros para, finalmente, nascer como essência "estética tecnicamente controlada" (DURAND, 1984, p. 487). Estamos remetendo o campo dos estudos sobre memória coletiva à modelagem dos símbolos universais segundo a derivação pedagógica do habitante das grandes metrópoles, nos termos de um "trajeto antropológico"8.

A partir destas preocupações teórico-metodológicas que o BIEV propõem situaçõesproblema aos aprendizes a antropólogos urbanos utilizando recursos tecnológicos diversos. Apesar da hegemonia da escrita já ter sido amplamente questionada pelas interfaces da fotografia e do cinema na Antropologia Visual, os desafios teóricos, conceituais e práticos são novamente atualizados com as emergentes problemáticas da metamorfose da escrita etnográfica na era das textualidades eletrônicas. Se o artefato livro permite, através de sua materialidade e interface, construir limites às práticas de leitura e escrita (CHARTIER, 1999), a produção da etnografia hipermídia transcende as barreiras da linearidade imposta pelas páginas impressas. Introduzindo a ruptura como textualidade (ECKERT\&ROCHA, 2015), o hipertexto possibilita leituras múltiplas do material etnográfico através de diferentes pontos de entrada que possibilitam que o leitor-navegador seja também um agente da construção interpretativa.

\footnotetext{
${ }^{7}$ O método de convergência se circunscreve dentro do estruturalismo figurativo de matriz durandiana e seus estudos sobre as vastas constelações de imagens que se agrupam e re-agrupam, por isomorfismo, ao redor de símbolos convergentes, dando origem a dois grandes regimes do imaginário e suas três estruturas.

${ }^{8}$ Isto é, "constitutivo de um acordo, ou de um equilíbrio - o que denominamos de trajeto - entre os desejos imperativos do sujeito e as intimações da ambiência objetiva", e no qual a função fantástica "modula a ação estética e social" de contar o tempo (Durand, 1984, p. 456-458).
} 
No processo de desterritorialização e desmaterialização da representação etnográfica gerada pela disponibilização na WEB, são possíveis novas formas de escrita que incorporem diferentes lógicas tanto para o texto quanto para outras mídias. Sendo um debate contemporâneo que permeia as discussões em torno da escrita etnográfica, devido à sua tradição de dar voz ao Outro por meio do espaço livresco, foi criado um blog denominado livro do etnógrafo por um grupo de estudos sobre escrita composto de pesquisadores no BIEV em 2009. No final de 2017, o projeto foi reestruturado e pode ser acessado em medium.com/livrodoetnografo ou através do portal biev.ufrgs.br onde estão expostas todas as produções do núcleo.

Fig. Nº 3: Capa do projeto livro do etnógrafo: apresentação da identidade visual inspirada nos livros de artistas desenvolvida por Matheus Cervo

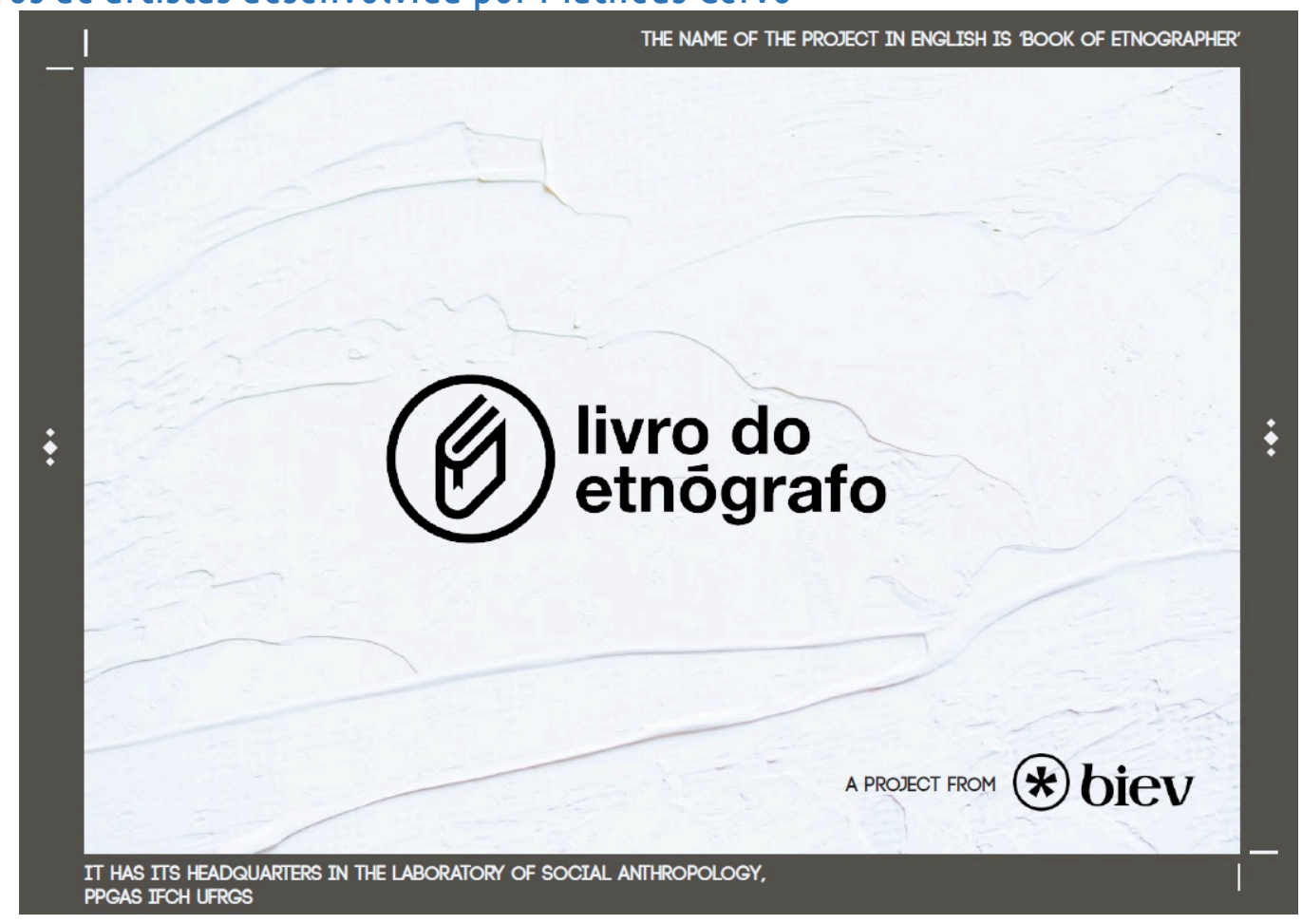

Com a finalidade de arquitetar um espaço virtual que fosse fruto da construção coletiva dos membros presentes e futuros da nossa equipe, o intuito do projeto é, para além de democratizar o conhecimento antropológico produzido na academia sobre Porto Alegre, refletir sobre diferentes usos de escritas, imagens, desenhos e sons nas diferentes etapas da pesquisa social através dos recursos digitais. Concedendo ao ruído, ao fragmento e ao inacabado um espaço de reflexão tão importante quanto uma escrita em moldes de impressão, expressamos nossa concepção da escrita etnográfica enquanto fenômeno temporal em que diversas técnicas 
e suportes materiais são mobilizadas para estruturação do pensamento conceitual e expressão da experiência em campo.

Refletindo sobre a figura do antropólogo como narrador (ECKERT\&ROCHA, 2003) das sociedades complexas (VELHO, 1981), os processos expostos no projeto exploram as diferentes modalidades nas quais a escrita desempenha algum tipo de papel na construção das etnografias sobre a memória urbana. Criado por um núcleo que trabalha com a construção de um banco de imagens de diferentes fundos de origem, sendo etnográficas ou não, os processos de escrita também estão atrelados a reflexões que envolvem produções multimídias e hibridizações das diferentes formas de captura do sensível.

São construídas seções, ao longo do tempo, para organização do conteúdo criado. As divisões criadas para navegação do usuário na plataforma possuem fundamentação teórica construída pelos aprendentes em seminários semanais nos quais são debatidos temas específicos em uma determinada conjuntura de interesses. No momento atual, o site está organizado em três seções que são constituídas por subdivisões a fim de densificar a reflexão de um processo de pesquisa específico.

Inspirados pelo tema da desterritorialização e descolonização dos saberes e fazeres antropológicos através da crítica pós-moderna à escrita etnográfica realista, adotamos as reflexões de Rancière para criar as divisões do livro do etnógrafo a fim de compreender o ato de escrever enquanto uma partilha do sensível (RANCIÈRE, 1995) em uma comunidade interpretativa. Há a dupla crítica à escrita pelas suas características de ser, simultaneamente, muda e falante demais: a letra inscrita na folha de papel é muda por ser uma letra órfã para lhe dar corpo através da oralidade e ser falante porque possibilita que qualquer um que tenha seu acesso the confira voz.

Desta forma, percebemos a tensão intrínseca à escrita devido seu trajeto antropológico (DURAND, 1984) na cultura ocidental judaico-cristã na qual é conferido estatuto de verdade às escrituras sagradas, ao discurso científico, aos documentos de Estado no apagamento da semelhança entre uma letra e o corpo que a cria. Inquietação relevante para pensar a representação etnográfica através da perturbação do literário, da aventura da letra e da sua potência de fabulação, possibilitando uma nova luz sobre a Antropologia (GEERTZ, 2001). Com essas intenções teóricas, nomeamos uma seção de "o corpo da letra", onde são exploradas três formas de escrita enraizadas na corporeidade do antropólogo e de suas técnicas. 
Fig. $n^{0} 4$ : Tela captura da plataforma medium onde está hospedado o projeto livro do etnógrafo na subseção "o corpo da letra"

M (4) Follow sign in Get started

\section{o corpo da letra}

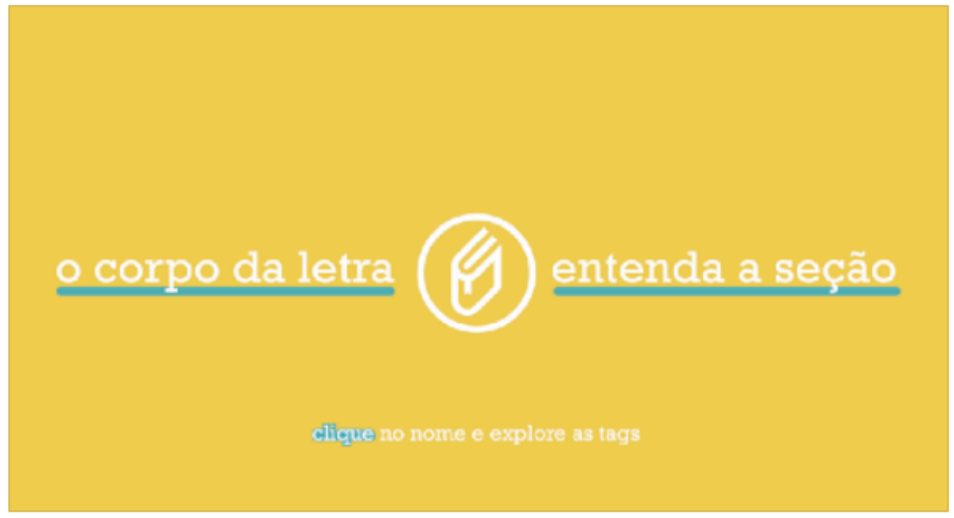

O que é "o corpo da letra"?

Entenda a seção

*) Biev ufrgs

Em tecendo a observação participante, a escrita é apresentada enquanto expressão das aventuras dos primeiros encontros etnográficos nos quais os laços de reciprocidade começam a ser concretizados. Sendo um dos momentos de maior hesitação para os aprendizes de etnógrafos na cidade, desenvolvemos diferentes problemáticas que surgem nas tentativas de aproximações de possíveis interlocutores para a pesquisa etnográfica. Se, por um lado, refletimos sobre atos de caminhar descompromissados (CERTEAU, 1998) em descrições das paisagens e movimentos citadinos onde uma distância entre o eu e o Outro ainda é grande, por outro lado, exploramos os momentos de maturidade da etnografia em que, após longos períodos de escrita e reflexão, retorna-se aos conhecidos companheiros de pesquisa.

Na subdivisão interiores da escrita etnográfica, são encontradas reflexões sobre os tempos compartilhados em campo, em contraposição aos tempos solitários que toda etnografia proporciona aos antropólogos. Considerando os escritos íntimos expressos em diários após o encontro com o nativo em campo, a dimensão da interioridade e o dialogo consigo mesmo é explorada enquanto um processo do pesquisador em uma gênese recíproca (DURAND, 1984) com a técnica da escrita. Pretendemos perspectivar a convergência das dimensões discordantes do tempo vivido e do tempo refletido (ROCHA; ECKERT, 2015, p. 147) na pesquisa social. 
Todavia, essas diferentes escritas dos diários de campo já são compostas de um trabalho de lapidação dos fragmentos cotidianos registrados fugazmente junto à alteridade: antes da construção dos densos relatos etnográficos, temos o instrumento primordial do caderno de notas - nome da última subseção. Na impossibilidade de construir o diário ao mesmo tempo que o etnógrafo compartilha das vidas dos pesquisados, são registrados rápida e desordenadamente nomes, laços de parentesco, desenhos.

Se o corpo da letra compõe um espaço em que as modalidades preliminares da escrita etnográfica monográfica são colocadas em foco, nossa segunda seção privilegia as aventuras do corpo do antropólogo em uma caminhada cosmológica em que poética, fábula e afeto se tornam elementos do desvendar o urbano. A seção Aventura do Corpo à Letra foi inspirada pela metodologia da etnografia de rua (ECKERT; ROCHA, 2003), já explicada no projeto anterior exposto, e possui duas subdivisões para organização de seu conteúdo.

Em Os Passos Perdidos da Etnografia, o etnografar a rua se manifesta na sua dimensão de tempo e movimento. O desafio é expressar a experiência vivida no ambiente das cidades em caminhos, ruídos, cheiros e cores que sugerem, sem cessar, direções e sentidos desenhados pelo próprio movimento dos pedestres e dos carros que nos conduzem a certos lugares, cenários, paisagens, em detrimento de outros (ECKERT; ROCHA, 2003, p. 4). Este espaço é destinado às reflexões dos deslocamentos na cidade e do pensar a si mesmo na paisagem urbana.

Por último, a subseção Rapsódias Urbanas acolhe observações sistemáticas dos lugares de sociabilidade de rua, das suas intensidades segundo os diferentes horários, o comportamento corporal dos indivíduos e/ou grupos nas esquinas, suas formas de interação nos bares e bancos de praças, suas regras de evitações, etc (ECKERT; ROCHA, 2003, p. 6). Cenários, lugares, personagens e acontecimentos: é dentro da proposta benjaminiana que a preocupação com o paradigma estético (MAFESSOLI, 1985) de interpretação das figurações da vida social na cidade se expressa na confluência hipermidiática em um ambiente de blog.

Entretanto, nosso espaço não pretende constituir reflexões onde o foco da expressão etnográfica está, apesar do uso conjunto de outros recursos midiáticos, somente no literário: quais as contribuições que os processos escriturísticos oferecem para os usos da imagem na produção dos saberes antropológicos? Na seção Interfaces da Escrita, apontamos a necessidade de construção de roteiros para produção de Antropologia Visual nas cidades com diferentes problemáticas conforme a mídia principal utilizada.

Concebendo os recursos tecnológicos enquanto prótese do pensamento, eles são parte de uma criação, e não apenas de uma aquisição, ao integrar um universo conceitual que não compreende tão somente o real (ECKERT; ROCHA, 2015, p. 142). A fim de evitar o emprego de 
recursos midiáticos diversos apenas como dados documentais de campo, salientamos o perigo de conceder à imagem técnica um estatuto de verdade no qual a "realidade" é demonstrada de forma fidedigna sem a presença e intencionalidade do antropólogo.

Desta forma, os roteiros de campo são expostos aqui pela perspectiva do subjetivismo bachelardiano (BACHELARD, 1993), permitindo refletir sobre o lugar do nosso imaginário na produção de narrativas etnográficas através dos recursos audiovisuais. Assim, foram criadas três subdivisões a fim de tornar visíveis os bastidores escritos de documentários criados e as respectivas reflexões em torno das implicações do uso de diferentes mídias em campo. As subseções são denominadas produção de ensaio fotoetnográfico, produção de crônicas sonoras e produção de crônicas videográficas.

\section{Práticas de ensino em Antropologia Visual}

Inspirados pelos estudos piagetianos e durandianos sobre a inteligência e o imaginário, consideramos que o conhecimento é um processo que resulta da forma incessante como interagimos com nosso ambiente cósmico e social, a partir do qual construímos uma representação calculável do real. Argumentamos, com base nos estudos de Yves Cheverald, que o ensino de Antropologia Visual permite pensar o ofício do antropólogo através da diferença entre o aprender saberes técnicos e científicos e o aprender saberes práticos: no último caso, o processo de conceituação permanece implícito ou parcialmente explícito para o sujeito que o exercita e o constrói na vida ordinária.

A partir dessas afirmações, adotamos os fundamentos epistemológicos nos quais os processos de formação de uma representação operatória do real que todo o conhecimento traduz, científico ou cotidiano, são fundados no modo de interiorização dos gestos e das percepções que orientam as trocas entre o sujeito e o seu objeto de conhecimento. Compreendemos representação, neste escrito, como um conjunto organizado de enunciados direcionados a um saber-fazer necessário à compreensão de situações onde os conceitos são apreendidos.

Segundo propõe G. Vergnaud (1985), há uma estreita vinculação entre o gesto e o pensamento no processo de produção do conhecimento. O aspecto seletivo da apreensão de uma informação baseia-se numa operação de seleção de gestos em relação à determinada situação. Para o autor, do estreito vínculo entre a seleção de gesto e de ordens de pensamento, nascem os esquemas, que são uma totalidade dinâmica funcional, correspondendo uma organização invariante de conduta referida a uma classe dada de situações. Neste caso, trata-se 
das situações onde podemos mergulhar os alunos para que aprendam o uso prático dos conceitos do campo da Antropologia audiovisual aplicada aos estudos de etnografia da duração (ROCHA \& ECKERT, 2013a) em contextos metropolitanos.

A ciência e a tecnologia, especificamente, aqui, os recursos audiovisuais e as redes digitais, traduzem-se, portanto, em uma representação calculável do real que surge para dar conta de situações com as quais nos confrontamos na produção etnográfica. A tecnologia tem por fundamento representações implícitas as quais, como fundamento de um conhecimento científico que se pauta por um saber explícito, precisam ser submetidas a um processo de rupturas epistemológicas que permita ao etnógrafo, ao empregá-las, avaliar as linguagens visuais nas quais foi socializado.

A trajetória de cada pesquisador, sejam aprendizes ou antropólogos consolidados, contempla a história de um conjunto de situações e de objetos encontrados na vida ordinária: são estas experiências que constroem um conjunto de invariantes operatórias que nos permite uma relação específica com o real. Nos termos de G. Vergnaud (1985), do caráter adaptativo do conhecimento humano resulta o conceito de situação didática.

Esta é a orientação que, para nós, marca a estrutura do ensino na disciplina de Antropologia Visual: os seus conceitos devem ser apreendidos através de situações-problemas postas aos alunos onde os recursos audiovisuais serão aplicados. Com estas intenções, reunimos os conceitos dos momentos pedagógicos aplicados ao processo de transposição didática onde as aprendizagens dos nossos alunos se realizam. Ao pensarmos os usos das tecnologias de captura audiovisual na produção do conhecimento antropológico nos nossos núcleos de pesquisa, partimos dos supostos da psicologia da inteligência que afirma que não há situações de aprendizagem, em termos de saberes científicos e saberes cotidianos, sem um sujeito munido de intencionalidade. É justamente a conduta do sujeito que faz um episódio de sua vida ou de qualquer outro se transformar em situação.

Assim sendo, o primeiro desafio no ensino da Antropologia Visual está em reconhecer que o uso dos recursos audiovisuais no campo científico se reporta a uma poética singular de diálogo estreito com os objetos, as suas propriedades, as suas relações enquanto que os saberes práticos tratam de uma poética mais próxima das situações diante das quais temos que agir diariamente e responder pessoalmente. Ou seja, todo o conhecimento traduz uma ação operatória com o real (PIAGET, 1975), mas não pode prescindir do papel da linguagem (VIGOTSKY, 2001) como elemento de sua transmissão a partir da mediação do Outro (WALLON, 1979), ou seja, o professor ou mestre (CHEVALARD, 1985). Afinal, tal como aponta esse último autor, "todo o conhecimento, é conhecimento do Outro", o que faz com que se reconheça aqui 
que "somos geneticamente sociais" na forma como o conhecimento se processa, constrói e transmite.

Com esses comentários breves, concluímos que os conceitos no campo da prática antropológica não são criados somente para que sejam expressos nos espaços livrescos, mas porque existem problemas práticos e teóricos a serem solucionados pela comunidade interpretativa de antropólogos que operam com a imagem no campo da produção científica. Constatação de suma importância para pensar o campo da Antropologia Visual, já que é somente ao final que os conceitos científicos que veiculam a subdisciplina tomam, finalmente, a forma de um texto.

Assim sendo, salientamos que aprender os conceitos por meio dos quais operamos as linguagens audiovisuais só adquire sentido se didaticamente oferecermos aos alunos uma multiplicidade de problemas aos quais eles correspondem. Outro aspecto importante é que tais conceitos não funcionam isoladamente, mas vinculados uns aos outros em uma ampla e complexa rede (WALLON, 2000) de um campo conceitual (VERGNAUD, 1993).

Trata-se das aprendizagens dos usos dos recursos audiovisuais por parte do antropólogo na prática etnográfica e no processo de construção do conhecimento de seu campo disciplinar, segundo as propriedades dos objetos aos quais se aplica, ou seja, as regularidades da sua natureza, ao alcance e aos limites de suas ações no contexto do trabalho de campo. Em nossa concepção, a aprendizagem dos usos dos recursos audiovisuais - não apenas no registro etnográfico, mas também no processo de construção do conhecimento antropológico -, resulta da atividade básica de resolver determinadas questões, organizando-se tais situações-problemas através de esquemas 9 .

Ressaltamos aqui o lugar estratégico, didático e pedagógico daquele que ensina em relação aquele que está em situação de aprendizagem. O professor se torna o responsável por criar situações didáticas envolvendo trabalho de campo onde os alunos serão desafiados a enfrentar problemáticas no uso dos recursos audiovisuais. As condições reais de ensinoaprendizagem, imposta pelos mestres, são, portanto, a própria condição do processo didático uma vez que o que está em jogo é a norma temporal imposta por ele para a temporalidade das aprendizagens dos aprendizes. Sara Pain (1985), psicopedagoga argentina, ensina-nos sobre a importância das aprendizagens dramáticas (além das aprendizagens lógicas) que constituem o processo de construção do conhecimento.

\footnotetext{
${ }^{9}$ Através das teorias de Vergnaud (1985), conceituamos esquema enquanto uma organização invariante de conduta para uma classe de situações dada.
} 
No nosso caso, estamos nos referindo a situações didáticas que tem o teatro da vida urbana, os itinerários dos grupos urbanos, suas trajetórias sociais e formas de sociabilidade como palco das ações de aprendizagens dos alunos para os usos dos instrumentos audiovisuais e hipermidiáticos. As proposições das situações se compõem de inúmeras tarefas que oferecem aos alunos desafios específicos no domínio das diferentes linguagens cujo objetivo central é a resolução de problemas para aprendizagem dos conceitos na prática.

Segundo aponta Yves Chevalard (1985), devemos reconhecer as diferenças das lógicas internas que regem: os saberes oriundos dos enunciados e conceitos que subsidiam e conformam a comunidade interpretativa da Antropologia Visual e da Imagem (objeto do saber/conteúdo a ensinar); os saberes específicos das linguagens audiovisuais aplicados concretamente à produção do conhecimento antropológico (objeto a ensinar/versão didática); e, por último, os saberes com os quais se opera a formação do antropólogo no trabalho de campo e as suas situações de aprendizagens da prática etnográfica audiovisual (objeto de ensino).

Fluxograma 1. Esquema de Yves Chevalard para pensar o ensino de Antropologia Visual.

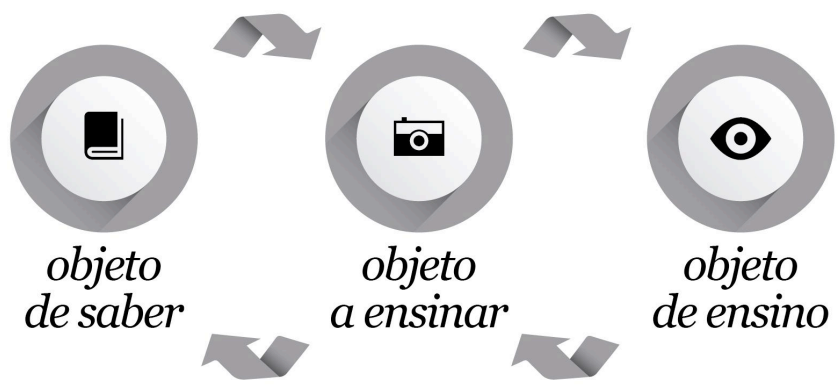

Isto posto, salientamos que a Antropologia Visual e da Imagem é um objeto de saber bastante complexo onde se conformam determinadas noções segundo um outro campo de conhecimento determinado - no caso das nossas experiências, nos conformamos a partir das problemáticas da Antropologia Urbana. Tais noções possuem certas propriedades, segundo as propriedades das linguagens de cada uma das tecnologias audiovisuais e a suas ocasiões de emprego, que nada mais são do que etiquetas para a comunidade de ensino. 
Fluxograma 2 - Expressão gráfica do esquema acima exposto.

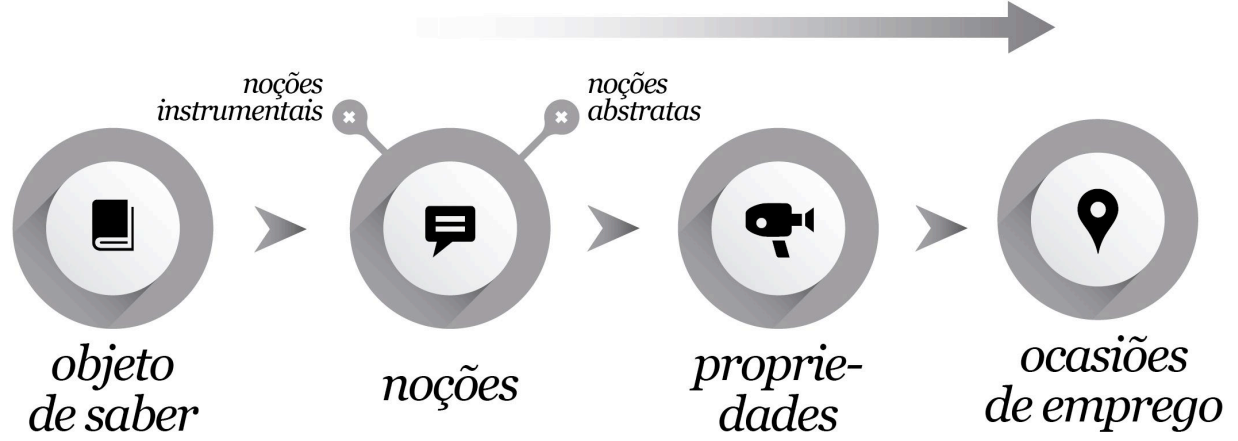

Com isto, torna-se relevante pontuar que o tempo da aprendizagem não é simplesmente um tempo progressivo que fixa a dinâmica do ensino num empilhamento cumulativo de "fatias" de saber que remontam à história didática do sujeito que aprende. Ao contrário, o tempo de ensino é passível de reorganização que desaloja esquemas anteriores já que suscita materiais de construção inéditos. Com esta démarche, nosso escrito apresenta reflexões relacionadas às experiências de ensino de Antropologia Visual no contexto universitário da UFRGS.

Com essa deferência ao ensino e às formas de transmitir o conhecimento, podemos tecer nosso projeto didático no ensino da pesquisa de antropologia com imagens, que está vinculado ao Programa de Pós-Graduação em Antropologia Social na Universidade Federal do Rio Grande do Sul. Primeiramente pela estruturação do Núcleo de Antropologia Visual (NAVISUAL) em 1989 no âmbito do Laboratório de Antropologia Social ${ }^{10}$ e, por outro lado, da criação, em 1997, do projeto Banco de Imagens e Efeitos Visuais (BIEV) a partir de proposta das professoras Cornelia Eckert e Ana Luiza Carvalho da Rocha, junto ao Núcleo de Estudos sobre Culturas Contemporâneas (NUPECs).

Ambos os projetos estão apoiados pela perspectiva didática de formação no encontro de duas linhas de pesquisa: por um lado a própria Antropologia Visual ou da Imagem, por outro lado, a Antropologia Urbana. Todavia, as rotinas de trabalho dos dois núcleos têm algumas especificidades que destacaremos acompanhado de duas experiências de ensino-aprendizagem

\footnotetext{
${ }^{10}$ Criado em projeto assinado pelos Professores Ondina Leal, Ruben Oliven, Ari Pedro Oro e pelo aluno de Ciências Sociais Nuno Godolphim.
} 
que resultaram em projetos etnográficos coletivos com diferentes experimentações dos recursos tecnológicos na cidade.

\section{REFLEXÕES SOBRE OS PERCURSOS: VISUALIDADES DA COMPLEXIDADE URBANA}

Preocupados com a disponibilização na WEB através da digitalização da produção etnográfica, compreendemos que fazer Antropologia Urbana com recursos audiovisuais e hipermidiáticos carrega consigo a importante tarefa de difusão das coleções sobre memória coletiva e sobre o patrimônio etnológico no mundo contemporâneo. Porém, ao contrário de utilizar as diferentes tecnologias como simples mecanismos para acumulação de um vasto banco de dados e para comunicação deste, compreendemos que o processo de ensino-aprendizagem deve ter como base que o saber-fazer na Antropologia Visual e hipermidiática necessita de uma série de rupturas epistemológicas que só podem ocorrer nas situações práticas e cotidianas de pesquisa.

Se refletimos, inicialmente, sobre o papel do mestre na orientação dos aprendentes nesta situação específica de pesquisa, também pensamos sobre como a criatividade no processo de inovação na pesquisa antropológica pode instaurar novas reflexões sobre as cidades. Assim sendo, concordamos com Achutti (2004) quando afirma que diferentes linguagens fornecem diferentes informações e necessitam de diferentes operações mentais para sua compreensão. Não poderíamos deixar de extender a reflexão do autor para as duas situações expostas neste escrito e as diferentes problemáticas que emergiram no nosso processo de captura do sensível através de diferentes tecnologias.

Apesar das especificidades das produções no BIEV ou no NAVISUAL, temos como uma base comum a prática da Antropologia Audiovisual enquanto uma experiência eticamente estética, como Jean Arlaud se atém (ECKERT; ROCHA, 2015). A escolha dos dispositivos técnicos reflete acerca dos dispositivos dramáticos e cênicos que conformam a experiência de captura do viver com o Outro, permitindo a construção do patrimônio humano com base em uma interpretação estética criada pela liberdade criativa do trabalho com imagens e ambientes multimidiáticos.

Importante salientarmos que todo processo inovador precisa manter sua filiação com os compromissos da Antropologia. Por isso nos valemos de A partilha do Sensível, de Jacques Rancière (2009), como um ato de conhecimento ao mesmo tempo que um ato político: para nós, a Antropologia Visual e da Imagem talvez tenha como principal papel a formação de uma comunidade interpretativa diferenciada nos quais os processos de restituição possuem suas 


\section{Antropologia com imagens}

especificidades. Entre os desafios, projetos, trocas, almejamos que este senso de partilha seja o mote que conduza ao espraiamento da linha de pesquisa, amenizando os limites burocráticos da circulação do conhecimento, democratizando as formas de aprendizagem e ampliando as ações públicas.

\section{REFERÊNCIAS:}

ACHUTTI, Luiz Eduardo Robinson. Fotoetnografia da Biblioteca Jardim. Porto Alegre: Editora da UFRGS, 2004.

BACHELARD, Gastón. La poétique de l'instant. Paris: PUF, 1993.

BENJAMIN, Walter. 0 flâneur. In: Walter Benjamin: Obras escolhidas. v. 3. São Paulo: Editora Brasiliense, 1989.

CAMPOS, R. Porque pintamos a cidade? Uma abordagem etnográfica ao graffiti urbano. Lisboa: Fim de Século, 2010.

CAMPOS, R. A pixelização dos muros: graffiti urbano, tecnologias digitais e cultura visual contemporânea. Porto Alegre: Revista FAMECOS, v. 19, n. 2, p. 543-566, 2012.

CAMPOS, Ricardo. A Arte Urbana enquanto "outro". V!RUS, n. 9, 2013.

CERTEAU, Michel de. A invenção do Cotidiano [1980]. Rio de Janeiro: Vozes, 1998.

CHARTIER, Roger. A aventura do livro, do leitor a o navegador. São Paulo: UNESP, 1999.

CHEVALLARD, Yves. La Transposition didactique: du savoir savant au savoir enseigné. Grenoble: La Pensée Sauvage, 1985.

Gilbert. Figures mythiques et visage de l'œuvre, de la mythocritique à la mythanalyse. Paris: Berg International, 1970.

DURAND, Gilbert. Sciencie de l'homme et Tradition [1975]. Paris: Berg. International, 1979.

DURAND, Gilbert. Les structures anthropologiques de l'imaginaire. Paris: Dunod, 1984.

ECKERT, C. ; ROCHA, A. L. C. . 0 antropólogo na figura do narrador. Habitus , v.

2, n.2, 2003.

ECKERT, C. ; ROCHA, Ana Luiza Carvalho da . Antropologias nas interfaces no mundo do hipertexto. Cadernos de Antropologia e Imagem (UERJ), v. 22, p. 27-44, 2007. 
ECKERT, C. ; ROCHA, A. L. C. . Etnografia da duração - antropologia das memórias coletivas em coleções etnográficas. 1. Ed. Porto Alegre: Marcavisual, 2013a.

ECKERT, C. ; ROCHA, A. L. C. Etnografia de rua: estudo de antropologia urbana. $1^{a}$ ed. Porto Alegre: Editora da UFRGS, 2013b.

ECKERT, C. ; ROCHA, A. L. C. A preeminência da imagem e do imaginário nos jogos da memória coletiva em coleções etnográficas. 1. ed. Brasília: ABA, 2015.

GEERTZ, Clifford. Nova luz sobre a Antropologia. Rio de Janeiro: Jorge Zahar, 2001.

MAFFESOLI, Michel. Le paradigme esthétique. La sociologie comme art. Sociologie et Société, v. XVII, n. 2., Ceaq, p. 33-39, 1985.

MANOVICH, Lev. The language of new media. London: The MIT Press, 2001.

MAGNANI, J. G. C. Festa no Pedaço. São Paulo: Editora Brasiliense, 1984.

MAGNANI, José Guilherme Cantor. Na metrópole: textos de antropologia urbana. São Paulo, EDUSP/FAPESP, 1996.

PAIN, Sara. Diagnóstico e Tratamento dos Problemas de Aprendizagem. $1^{\text {a }}$ ed. Porto Alegre: Artmed, 1985.

PÉTONNET, C. A observação flutuante: exemplo de um cemitério parisiense. 1982. Traduzido por Soraya Silveira Simões. Antropolítica, n. 25, p. 99-111, 2008.

PIAGET, J. A construção do real na criança. Rio de Janeiro: Zahar, 1975.

PIAGET, Jean. A Epistemologia Genética. São Paulo: Abril Cultural, 1978a.

RANCIÈRE, Jacques. 0 desentendimento. São Paulo: Editora 34, 1996.

RANCIÈRE, Jacques. Políticas da Escrita. São Paulo: Editora 34, 1995.

RANCIÈRE, Jacques. A partilha do Sensível: estética e política. 2a Ed, São Paulo: Editora 34, 2009.

ROCHA, A. L. C. Tecnologias audiovisuais na construção de narrativas etnográficas: um percurso de investigação. Cam pos (UFPR), v. 04, p. 113-134, 2003.

SILVA, Hélio R. S. Travesti, a Invenção do Feminino. Rio de Janeiro: Relume-Dumará, ISER, 1993.

SILVA, Hélio R. \& MILITO, Cláudia. Vozes do Meio Fio. Editora Relume \& Dumará, Rio de Janeiro: 1994.

VELHO, Gilberto. Individualismo e Cultura, notas para uma Antropologia das sociedades complexas. Rio de Janeiro: Zahar, 1981. 
VERGNAUD, Gérard. Concepts et schème dans une théorie opératoire de la représentation. Psychologie Française, n. 30, pp. 245 a 252, 1985.

VERGNAUD, Gérard. Teoria dos Campos Conceituais. Anais do $1^{\circ}$ Seminário Internacional de Educação Matemática do Rio de Janeiro, p. 1-26. Rio de Janeiro,1993.

VIGOTSKY, Lev Semionovitch. A construção do Pensamento e Linguagem. São Paulo: Martins Fontes, 2001.

WALLON, Henri. As origens do pensamento na criança. 34. Ed. São Paulo: EDUSP, 2000.

WALLON, Henri. Do acto ao pensamento. Lisboa: Moraes, 1979.

WHYTE, William Foote. Sociedade de esquina [1943]. Rio de Janeiro: Jorge Zahar Editor, 2005. 